\title{
Features of Information Technologies Influence on Social Development
}

\author{
Ludmila N. Shcherbakova \\ Department of Economic Theory \\ and Public Administration \\ Kemerovo State University \\ Kemerovo, Russia \\ ludmilashc@yandex.ru
}

\author{
Ludmila L. Zobova \\ Department of Economic Theory \\ and Public Administration \\ Kemerovo State University \\ Kemerovo, Russia \\ 1lzob@mail.ru
}

\author{
Elena K. Evdokimova \\ Department of Economic Theory \\ and Public Administration \\ Kemerovo State University \\ Kemerovo, Russia \\ elena evdokimova@inbox.ru
}

\author{
Svetlana A. Savintseva \\ Department of Economic Theory \\ and Public Administration \\ Kemerovo State University \\ Kemerovo, Russia \\ ssa svet@mail.ru
}

\begin{abstract}
- the article describes a dual impact of digital revolution on various spheres of human activity and social relations, such as administration, education, science, health, ecology, finance, and trade, and income differentiation, monopolization of the markets, "consumerism" and creative abilities of human development. The work presents the advantages and disadvantages of information revolution implications. Production relations in the single information space (based on cloud technology, Big Data, information openness, and social networks) are opposed to the deepened digital divide. New opportunities for the development of education, science, health, and environmental sustainability are opposed to innovation inequality and deepened environmental imbalance. Information technologies helped improving the efficiency of the activities in the financial sector, but the gap between the financial and the real sectors of the economy increased. The level of organization rose significantly due to the continuity of decision-making and communications, while at the same time the introduction of information technologies increased the bureaucracy. Stiff competition of information companies is combined with the risk of global monopoly. On the one hand, the information revolution gave broad opportunities for developing creative activities; while on the other hand, it has led to the loss of Internet users' social mobility.
\end{abstract}

Keywords-information and communication technologies, information diversity, consequences of the digital revolution, the digital divide, e-Government, online finance, electronic Commerce, informational monopolism, online consumerism.

\section{INTRODUCTION}

Modern society is formed on a platform of the information revolution which affects all aspects of the society. The systemic feature of information economy is the need for information equality. In reality, the nature of its impact on the society has both positive and negative features. The purpose of this article is to reflect on the ambiguous influence of the information revolution on social relations and social development. The object of the research is the deformation of social development as a consequence of the acceleration of social processes generated by information technologies. The positive result of the information economy is possible within a single global information space. At present, the world information space can be characterized as a common information space where digital spatial inequality has formed.
Structural deformations and risks identified in this article will help in creating measures to address them.

\section{FEATURES OF INFORMATION ECONOMY}

In the late $20^{\text {th }}$ century and the first decade of the $21^{\text {st }}$ century, information economy was the object of numerous studies, and a lot of research was devoted to understanding its content, systemic qualities, and its effect on the society and the economy. In modern conditions, the term "digital economy" has been more topical, and in this regard, the question arises whether it is an analogue of information economy, a new stage of its development or a fundamentally new economic phenomenon. The unity of these two phenomena is obvious. Both information economy and digital economy have common evaluation criteria: technological, economic, labour, spatial, consumer and creative, the importance of each of which will be determined by the increase of the role of information technology (IT) in the corresponding sphere.

Any new technology goes through two stages of development: its internal, "latent" development and the effect of overflow, when the power of this technology begins to be used in the national economy and to influence on the culture, science, consumer behavior, lifestyle, communications, advertising, and political issues. A new stage in the development of information technologies is associated with the active application of the breakthroughs of digital revolution in the society and the economy. Digital economy is understood as a policy of using digital transformations for innovation, growth and social prosperity. [1: 10].

Information flows of the 21 st century have a number of features that allow for effective influence on all aspects of the human life. Firstly, modern information is intangible, virtual, which enables its combination with any material resources, and its easy penetration into various spheres of activity. The diversified nature of modern information is explained by a number of reasons. Firstly, the modern IT material carriers and computers are equally applicable in various industries, and differ only in related software services. The information itself is a "raw material", a primary resource in any sphere of activity. Secondly, the availability of information has increased significantly due both to the increase in the speed of processing and transmission of information, and to its affordable cost. Over the past 10 years, the speed of 
international Internet traffic has increased by almost a hundred times [2]. Prices for information products are characterized by both positive and negative dynamics. The data, whose storage cost $\$ 150000$ in 1970, is now stored for $\$ 0.01$ [3]. A significant change in the parameters of information use resulted not only in the reduction of costs and increase in the efficiency of production processes, but also in the increase in the volume and value of information exchange between consumers, states, and carriers of cultural values.

The information economy objectively requires a single information space, but there are limitations to its real functioning.

The need for a common information space is based on the information of a new quality, and the role of the mobile and cloud technology sector is growing. According to forecasts, the cost of public cloud services in the world will increase five times in 2013-2018 [4]. But the dynamics of cloud technologies is hampered by the fragmentation of information entities. The logic of this technology is that attempts to control the data within one enterprise are meaningless. Perimeter security moves beyond the perimeter, changing the role of the service directories. Cloud technologies stimulate mutual development, and in the future, most of the information budgets will be directed to the integration of services.

The trend of integration in the information exchange relations is associated with an increase in the role of open data compared to closed data. The status of information as an object of copyright leads to the fact that a large amount of information is closed; as a result there are difficulties with the processing of information and its further distribution. Supporters of open data create Open Data Councils, which include representatives of expert communities, authorities and the information sector. They argue that the access nondiscrimination as a crucial feature of information is directly related to the openness of data.

The importance of the factor of equal access and sharing information is manifested in the formation of the Internet of Everything (IoE) and the creation of Big Data, which include databases of a new level, whose major features are a large volume and the high speed of data transmission [5: 50-52]. The development of Big Data technology depends on the number of participants and their willingness to share information, so the digital backwardness of developing countries is an obstacle to realizing all the benefits of Big Data to their full.

Social networks as an organizational form were initially focused on the mechanism of interaction, as the behavior of their participants depends not on their internal motivations, but on the structure of the network; the increase in the effectiveness of the work depends on all participants of the network. Sustainable network interaction of their agents provide for positive externalities. In practice, the international community has adopted documents that contribute to the formation of a common global information space, not a single one. These two types of information space differ at the level of control mechanisms.
The most advanced information technologies are more focused on joint production and consumption of information. Since almost all the spheres of human activity are information-consuming industries, the integration processes should affect science, culture, ecology, health, economy, education, and consumer behavior.

The ambiguity of the impact of digital technologies must be taken into account. Most of the acts of using information are carried out in the virtual space, and the speed of operations is accelerated - as a result, both of these factors can contribute to the formation of opportunistic behaviour of the transactors, who would turn the advantages of IT into their personal benefits.

\section{THE RISKS OF DIGITAL ECONOMY}

\section{A. The Digital Divide}

Despite the emerging integration of the information space and the global institutions' focus on narrowing the information gap in the development of certain countries, a new form of social differentiation - the digital divide - is being formed. The digital divide reflects the inequality in the income of business entities based on the use of information resources [6].

The digital divide can manifest itself in two forms: the reproduction inequality, which is characterized by the projection of the model of information sector development on the existing relations of inequality, and the dynamic inequality in which some countries use their advances in information and communication technologies (ICT) seeking for the spatial and time rent.

The first form of digital inequality manifests itself at the inter-state level. The International Telecommunication Union annually compiles the index of ICT development, which is an integral index including 11 separate indicators. One of the aims of the index is measuring digital differentiation.

The index of information development has a wide range of fluctuations both between and within regions. There is a big gap in the level of IT development within the regions (see Table I).

TABLE I. THE INDEX OF INFORMATION DEVELOPMENT IN THE MOST ADVANCED AND THE MOST BACKWARD COUNTRY IN EACH REGION REGION $[7: 65]$

\begin{tabular}{|l|l|c|l|c|}
\hline \multirow{2}{*}{\multicolumn{1}{|c}{ Region }} & \multicolumn{2}{c|}{$\begin{array}{c}\text { The most advanced } \\
\text { country }\end{array}$} & \multicolumn{2}{c|}{$\begin{array}{c}\text { The most backward } \\
\text { country }\end{array}$} \\
\cline { 2 - 5 } & \multicolumn{1}{|c|}{ Country } & Index & \multicolumn{1}{c|}{ Country } & Index \\
\hline $\begin{array}{l}\text { North and South } \\
\text { America }\end{array}$ & USA & 8.18 & Cuba & 2.91 \\
\hline Europe & Iceland & 8.98 & Albania & 5.14 \\
\hline CIS countries & Belarus & 7.55 & Kyrgyzstan & 4.37 \\
\hline $\begin{array}{l}\text { Asia-Pacific } \\
\text { region }\end{array}$ & Korea & 8.85 & Afghanistan & 1.95 \\
\hline Arab countries & Bahrain & 7.60 & Comoros & 1.82 \\
\hline Africa & Mauritius & 5.88 & $\begin{array}{l}\text { Central African } \\
\text { Republic }\end{array}$ & 1.04 \\
\hline
\end{tabular}


A particularly large gap is observed in the use of information-processing technology and modern technologies: broadband mobile communication, Big Data, and converged infrastructure. There is a difference between countries in the level of e-Government development. Differences are particularly noticeable in developing countries: Brazil, Colombia, Honduras, Bolivia, and South Africa. Despite improvements in the information indicators of developing countries, broadband services accounted there for $26 \%$ GNI per capita, while the accepted norm is $5 \%$ [7:70-90].

The second form of digital inequality manifests itself in digital spatial competition and even information wars. The dominant position of the subject in the information space allows minimizing time costs and maximizing profits.

The effect of digital spatial inequality leads to structural deformation of the national economy. Structural distortions are caused by the migration of savings and consumer spending of high-income classes of the society abroad (overseas education and health services, buying real estate and consumer goods), and the formation of the sector of goods and services for the rich. The opportunities for the development of certain sectors of the national economy are reduced. The amount of income losses in mass production industries, which is equal to the outflow of consumer spending, can be calculated mathematically. These losses deepen structural deformations, and the deeper the deformation, the greater the inequality. Thus, the structure of the economy can be improved through the impact of information technology on structural deformation. To do this, it is necessary to reduce certain spheres of activity and stimulate the development of other sectors for application of labor and capital.

\section{B. The Impact of IT on the Management Process}

The use of information technologies in management provides it with a higher level of organization, as the main components of management (decision-making and communication) become inseparable. Modern information resources make it possible to perform each stage of work with information more effectively.

Public administration is turning into the e-Government that has great potential for more economical and cost-effective management of the economy. This is due to the fact that it can simplify and speed up the exchange of information and improve the coordination of separate entities' actions, both within individual firms and the region's public authorities. Interactive online meetings can ensure the growth of management dynamics and reduce administrative costs.

Information and communication technologies can have other applications in the management process and serve as a catalyst for bureaucratization. The costs of e-Government in most countries are growing, but the effectiveness of management remains almost the same, which confirms the convergence of information and bureaucracy in a single system. Control of information is evolving into management abuses leading to the emergence of an information and bureaucratic system.

\section{The Impact of IT on the Development of Science, Health, and Environmental Issues}

Knowledge, science, and education are public goods tending to equal consumption, and modern information has a similar property. Information technologies strengthen the component of integration and equality in the consumption of intellectual goods. Innovative models of modern type require diffusion of global knowledge. In the production of global knowledge itself, the role of interactions through information technology is increasing. New opportunities for scientific cooperation appear due to remote scientific communities, modern network technologies in scientific research, and virtual laboratories. Research teams can be formed on a distributed basis, which means the team members in different locations connected by information networks.

The management system in scientific organizations is changing: vertical innovation systems are being abandoned, and horizontal network models of organization are being formed at all levels of management instead of them - this corresponds to the idea of management in the information society.

At the same time, the use of information technologies can negatively affect the development of the knowledge economy, because of the increasing risks of inequality in innovative leadership, new forms of scientific knowledge theft and asymmetric information provision, and the basis for systemic uncertainty of information is increasing to some extent.

The information and communication sector has a progressive impact on the health of the population through:

- development and dissemination of new medical and diagnostic equipment and treatment technologies;

- exchange of specialists and their experience between different regions. In modern conditions, the hospitals that actively cooperate with the mass media develop best;

- promoting the healthy way of life through the mass media.

The information society has great opportunities for the "greening" of the society and the economy. The interrelation of ecologization and informatization was obvious for the theorists of the information society. They hoped that the information society had a globalist spirit in which people and nature could live together in harmony. However, a developed information society can contribute much more to the improvement of the environmental situation. It creates phenomena that provide the basis for solving environmental threats: the formation of a collective mind; formation of a different value system; the society's focus on eradicating the sharp differentiation of incomes; ensuring equal access to new factors of production: knowledge and information, without which solving environmental problems is impossible.

At the same time, active promotion of information technologies without certain control can lead to aggravation of contradictions between people and nature and deterioration of health capital. 


\section{The Deformation of Social Development.}

IT has dual influence on the proportions in different sectors of the economy, which subsequently affects the social aspects of human life. The financial sector of the economy, as an active part of the information-consuming industries, is a striking example of the embodiment of IT facilities into extra profits. The growth of debt obligations, derivatives, electronic money, fictitious and speculative demand was stimulated by the digital revolution.

At the micro level, there are special information systems for processing and analyzing the information on financial management and customer relations (CRM), accounting and tax accounting, distribution, staff accounting and payroll. At the same time, the internationalization of the financial sector that took place on the basis of the dynamic development of information and communication tools acted as a catalyst for the imbalances between the financial and the real sectors [8]. The financial structures' use of electronic means of service led to their running in real time, and the distance lost its former importance. The formed global network finances have a high degree of instability, including spatial and temporal risks. The richest actors of the financial market seek to increase profits and win over competitors with the help of new technologies, so the unity of the financial network is impossible. On the contrary, the financial network is characterized by gaps, imbalances and a crisis situation, which resulted in the 20082009 financial and economic crisis.

As a result, social tensions were mounting, as cyclical fluctuations caused by the asymmetry of financial markets and the real sector have led to the loss of depositors' income, currency fluctuations, and increased credit debt.

IT had a dual impact on trade (e-Commerce). IT provided two unique marketing advantages to online trading: firstly, the global virtual electronic market, and secondly, the Hypermedia as a new means of communication. The development of mobile devices and the growing role of social networks have provided an even greater surge in e-Commerce. Investment in e-Commerce is expected to grow by an average of $12.5 \%$ per year over the next five years [9].

E-Commerce has brought the phenomena that increase instability into the society and the economy. Online trading is used by unscrupulous sellers to strengthen their positions in the form of certain competitive advantages on the basis of unfair ways of doing business. Sellers renounce their obligations and operate illegally. The virtual nature of eCommerce makes it possible to act against the interests of the consumer, namely:

- the goods received by the consumer often do not correspond to the consumer's requests (colour, size, delivery time);

- non-traditional products are marketed.

Fraud in the Internet is explained by the formation of hybrid artificial societies with a range of behaviors, including cheating, and a different nature of time on the Internet - the speed of all operations. Fraud is realized both by means of fictitious trading platforms and copies of legal websites, and through the use of viruses and malware for stopping the work of online stores, hacking websites of online stores and Internet service providers. The frequency of fraud attempts is increasing: in 2016, the amount of fraudulent transactions increased by $19 \%$ compared to $2013, \$ 0.057$ per every $\$ 100$ of commercial trade is stolen [10].

\section{E. Monopoly and Competition in the Information Society}

The assessment of monopolistic trends in the information sector is not unambiguous. There is a view that there is no monopoly in that market. However, the scale effect manifests itself in the work of information companies, both on the parts of the demand and the supply, which is the basis of monopoly. In addition, the global nature of the information resource raises concerns about the monopolization of the planetary information system.

Of course, there is a competition between information companies. The situation with certain privileges in making profit only warms the degree of its intensity. Information companies are known to have kept the position of maximizing revenues during the world economic crisis of 2008-2009, despite the reduction in the overall growth rate. Google, Yandex, and $I B M$ showed growth of revenue profits instead of slowing, and even showed intensification of investment activities. The rate of revenue from selling shares of the largest information companies in the world is high. The current price of their shares is usually two or more times as high as than the offering price, which is typical, for example, of Alibaba and Twitter [4]. Informational and spatial competition of information companies has a number of characteristic features: it is quite tough; the number of subjects of spatial information competition is increasing at the expense of developing countries. As a result of global competition, and hence international information competition, the division of countries into central countries and the countries of the information periphery is deepening, which changes the structure of the information space. The result of spatial digital competition is digital spatial inequality. The objective of spatial competition is receiving and keeping the spatial rent. The modern information technologies change the perception of the value of time by reducing the cost of transmitting ideas significantly. Thus, the heterogeneity of the global information space gives an objective opportunity to obtain extra income or the spatial and the time rent.

\section{F. "Consumerism" and individuals' creative activity as the results of information influence}

The information economy also has a controversial impact on consumption. The information society as a society with a new system of values can oppose the society of mass consumption by its very nature. The modern form of consumer distortions is "consumerism", in which the individual's goals are maximizing the number of purchased goods and the desire to move from one level of consumption to another, and the individual becomes the object of market forces. In turn, the market pushes people to numerous purchases, regardless of their real needs, and advertising strongly contributes to this. 
With the help of modern information and analytical systems, it is possible to achieve a successful solution to the problem of conformity of production and consumption and their proportional development. For example, in a number of countries the concept of ethical consumption has already been recognized, in the US and Europe more than $60 \%$ of buyers agree with the importance of ethical consumption [11: 151]. Information technologies can contribute to changing people's way of thinking and educating creatively thinking people through creating educational programs, promoting the role of knowledge and information, and properly organized way of life. Social networks can form groups following this direction [12].

In the context of the post-industrial technologies development, an alternative socio-economic development strategy is formed, where a different quality of an individual (homo creator) and the creative content of their activities become a new driving force. Development strategy should be focused on priority development of the create sphere [13: $128]$.

The Internet significantly influences the consumer behavior of Russians, especially that of the young people. $51 \%$ of young Russians use the Internet 24/7, $29 \%$ of them spend more than 5 hours a day on the Internet, and $19 \%$ browse the Internet 1-3 hours a day [14]. The real consequence is that instead of the simplicity and cheapness of obtaining information from the Internet, young people under the influence of advertising make more irrational purchases, perceives being constantly online as a vital norm, and loses mobility because of the passive waste of time on the Internet for entertainment purposes [15]. Studies in many countries have shown that young people are exposed to the so-called Internet addiction. The internet addiction exists all over the world, and the common access to the computer and the internet technologies in developed countries supports the spreading of this phenomenon. The research of this situation is still at its initial stage, but it is already evident that the losses in the so-called «Cyber Community» are caused by people's ignoring the other important aspects, such as the time spent with their families and friends, and the time spent on working. The new form of psychological addiction demands for active participation of the experts, especially those involve in studying Internet addiction, for developing and implementing special programs for junior and middle school students [16: 708; 17].

The diversified nature of modern information makes the task set by the Russian government to turn the information sector into a driver of economic development reasonable and logical [18]. Russia adopted the program of joining the information society later than most developed countries, but by the end of the first decade of the $21^{\text {st }}$ century the growth rate of information began to increase. The volume of electronic transactions is increasing; the demand and supply in the sector of Russian information technologies are expanding without the participation of the state.

At the same time, special attention should be given to the important aspect concerning not only the importance of using information technologies in the Russian society but also the possibility of their introduction and use. Russia ranks 45 th in terms of information development and ranks second in its group after Belarus [7: 65]. In 2016, the Russian Federation ranked second among the CIS countries and first in BRICS by its 'network readiness'. Yet, in the general rating of 143 countries Russia kept its $41^{\text {st }}$ place. According their network readiness, the place of the CIS and BRICS in the global informational space can be characterized as semi-peripheral.

However, Russia's information gap is manifested in a high degree of import dependence in the production of information and communication technology, underdeveloped foundations and practices of e-Commerce, weak use of information technology in government regulation, and the use of imported software with a closed code. The specificity of digital inequality is characterized, on the one hand, by an active growth in the use of information technologies [19], and on the other hand by the simultaneous loss of its dynamics due to structural information deformations (missed opportunities for development; the benefits of the use of information technologies obtained by entities or structures that either operate illegally or focus on cybercrime). In the studies conducted in the Russian Federation, attention is drawn to the so-called "socio-psychological threats" that arise when working in the digital environment [17].

The Russian Federation ranks 50th by the sub-index of the use of information technologies by the major stakeholders of the society: the government, enterprises, and individuals (while China ranks 53rd and India ranks 84th). As far as the subindex of economic and social impact of information and computer technologies is concerned, the average rank of Russia is $41 \mathrm{st}$ (while China ranks 39th and India ranks 74th). By the subindex of the ICT environment, including the political and business innovations, the average rank of the Russian Federation is 72 nd (while China ranks in the 81 st place, and India ranks 78th). [20]

Thus, based on the four average indicators, Russia ranks in the 48th place, while China ranks in the 60th place and India ranks $79^{\text {th }}$. The Russian Federation's indicators demonstrate its strengths and weaknesses. Russia ranks in the top one third of the rating by the levels of readiness, use and impact, but it shows weak development of the information and communication environment. The positive impact of the ICT is expressed in its economic and social effect. Yet, we can expect the negative consequences of introducing the information and computer technologies that the other countries had already faced.

Another problem for the Russian Federation is the mismatch between the modern level of information technologies' development and the level of social development (Russia ranks in the $61^{\text {st }}$ place in the world concerning the quality of life). Thus, Russia has a provision for the development of its economy and social sector by the means of the information sector. 


\section{CONCLUSION}

Thus, without denying a huge potential of digital economy and its transforming impact on the economy and society, modern information policy should become a complex diversified tool for managing social development, taking into account all possible consequences of the use of IT. Crossboundary, cross-sectoral and multi-stakeholder risks are emerging in the digital economy. There is no confidence in the control and security of personal information. The purpose of information development should be not only to stimulate the introduction of IT, but also to find tools that would hinder the formation of such negative structural imbalances as the expansion of bureaucracy, electronic fraud, financial speculation, monopolistic pressure, and loss of consumer mobility of households that have arisen in digital economy. The growth of economic efficiency based on information factors provides the basis for attracting new resources based on the knowledge and scientific achievements. Information policy can contribute to a new information culture through the Internet and social networks.

Russia's position in the global economic and information environment can be characterized as the presence of two different trends: the loss of information advantages on the basis of the general state of the economy and the potential for information development. In Russia, the institutional lag behind developed countries, a large degree of import dependence in the production of information and communication technology, the widespread use of imported software. At the same time, Russia has developed a set of new tools aimed at the interaction of business and science; there are advances in the scientific and educational sphere, and actively developing information technologies in the education system. The optimization of the Russian economy structure is possible on the basis of the information economy potential realization based on the digital alignment and feedback effect on the level of information development of individual industries. Russia has the opportunity to gain competitive information advantages through the diversified nature of the Russian information resource due to: the dynamics of e-business, faster development of e-Commerce, and strong positions of Russian programmers.

\section{REFERENCES}

[1] OECD Digital Economy Outlook 2017, OECD Publishing, Paris, 323 p. DOI:http://dx.doi.org/10.1787/9789264276284-en

[2] Measuring the Information Society Report, 2016. URL: http://www.itu.int/ru/ITU-D/Statistics/Pages/publications/mis2016.aspx (accessed on 25.11.2017).

[3] Trends in Telecommunication Reforms Report, 2016. URL: http://www.kanlink.ru/news/tendencii_v_reformirovanii_ehlektrosvjazi/ 2016-04-06-437 (accessed on 12.07.2016)

[4] Review and assessment of the development perspectives of the global and Russian information technology markets. URL: https://habrahabr.ru/company/moex/blog/250463/ (accessed on 25.11.2017)

[5] V. V. Volkov, D. A. Skougarevskiy, and K. D. Titaev, "Problems and prospects for studies based on Big Data (the case of sociology of law)", in Sociologicheskie issledovaniya [Sociological Studies], vol. 1, pp. 48$57,2016$.
[6] V. A. Shabashev and L. N. Shcherbakova, "Trends of the digital divide/equality in contemporary world", in Sociologicheskie issledovaniya [Sociological Studies], vol. 9, pp. 3-12, 2016.

[7] Measuring the Information Society Report 2017: Internatinal Telecommunicatin Union, 2017.

[8] V. D. Milovidov. "Information asymmetry and big data: should financial market paradigm be revised?", in World Economy and International Relations, 2017, vol. 61, no. 3, pp. 5-14 DOI: 10.20542/0131-2227-2017-61-3-5-14

[9] The Internet: figures and facts. URL: http://www.bizhit.ru/150916 (accessed on 15.09.2016)

[10] Some interesting analytics on the methods of fraud in e-Commerce // Analysis of fraud in e-Commerce URL: http://psm7.com/security/interesnaya-analitika-o-sposobax-moshennichestvav-elektronnoj-kommercii.html (accessed on 15.01.2017).

[11] M. A. Shabanova and T. A. Gitsalova, "Social economic factors for developing ethical consumption in contemporary world: Is there a future in for Russia?", in Sociologicheskie issledovaniya [Sociological Studies], vol 3, pp. 150-160, 2015.

[12] Zhaofeng Bu, Xiaoming Du, Bin Liu, and Ning Zhu. "Research on online education architecture based on xAPI technology", in Advances in Social Science, Education and Humanities Research (ASSEHR), vol. 206. International Conference on Advances in Social Sciences and Sustainable Development (ASSSD 2018), 2018.

[13] A. I. Kolganov and A. V. Buzgalin, "Polemical notes on purposeful accentuations in alternative social and economic strategy", in Sociologicheskie issledovaniya [Sociological Studies], vol. 3, pp. 120 130, 2014.

[14] I. S. Shapovalova, "Internet-communications impact of behavior and intellectual development of young people", in Sociologicheskie issledovaniya [Sociological Studies]. vol. 4, pp. 148-151, 2015.

[15] P. Kolozaridi and A. Shubenkova. "The Internet as a matter of social policy in Russian official discourse: a "good" or a "threat"?", in Journal of Social Policy Studies, vol. 14, no. 1, pp. 39-54, March 2016.

[16] A. Bruno, G. Scimeca, L. Cava, G. Pandolfo, R. A. Zoccali, and M. R. A. Muscatello, "Prevalence of internet addiction in a sample of southern italian high school students", in International Journal of Mental Health and Addiction, vol. 12, no. 6, pp. 708-715, December 2014.

[17] A. Sharikov. "Digital Literacy: a four-component model", in Journal of Social Policy Studies, vol. 14, no. 1, pp. 87-98, 2016.

[18] The Russian Federation Government Decree No 1632-p dated 28.07.2017 "On approving the program "Digital economy of the Russian Federation" URL: http://base.garant.ru/71734878/. (accessed on 25.11.2017).

[19] Digital economy indicators: 2017. URL: https://www.hse.ru/primarydata/ice2017 (accessed on 25.02.2018)

[20] S. Baller The Global Information Technology Report 2016 innovating in the Digital Economy, World Economic Forum Soumitra Dutta, Cornell University page at. URL: https:// www.weforum.org/gitr (accessed on 31.01.2018). 